\title{
Word priming in schizophrenia: Associational and semantic influences
}

\section{Citation}

Nestor, Paul G., Olga Valdman, Margaret Niznikiewicz, Kevin Spencer, Robert W. McCarley, and Martha E. Shenton. 2006. "Word Priming in Schizophrenia: Associational and Semantic Influences." Schizophrenia Research 82 (2-3) (February): 139-142. doi:10.1016/ j.schres.2005.10.010.

\section{Published Version}

doi:10.1016/j.schres.2005.10.010

\section{Permanent link}

http://nrs.harvard.edu/urn-3:HUL.InstRepos:28615074

\section{Terms of Use}

This article was downloaded from Harvard University's DASH repository, and is made available under the terms and conditions applicable to Other Posted Material, as set forth at http:// nrs.harvard.edu/urn-3:HUL.InstRepos:dash.current.terms-of-use\#LAA

\section{Share Your Story}

The Harvard community has made this article openly available.

Please share how this access benefits you. Submit a story.

\section{Accessibility}




\title{
Word priming in schizophrenia: Associational and semantic influences
}

\author{
Paul G. Nestora,c, ${ }^{\star}$, Olga Valdman $^{a}, b$, Margaret Niznikiewicz ${ }^{a}$, Kevin Spencera $^{a}$, Robert W. \\ McCarley ${ }^{\mathrm{a}}$, and Martha E. Shenton ${ }^{\mathrm{a}, \mathrm{b}}$ \\ ${ }^{a}$ Clinical Neuroscience Division, Laboratory of Neuroscience, Boston VA Health Care System- \\ Brockton Division, Department of Psychiatry, Harvard Medical School, Boston, MA, United States \\ bSurgical Planning Laboratory, MRI Division, Department of Radiology, Brigham and Women's \\ Hospital, Harvard Medical School, Boston, MA3 Department of Psychology, University of \\ Massachusetts, Boston, United States \\ 'Department of Psychology, University of Massachusetts, Boston, United States
}

\begin{abstract}
We examined semantic vs. associational influences on word priming in schizophrenia. Tested on three occasions, subjects made speeded lexical decisions to three kinds of prime-word relationships: semantic-only (e.g., Deer-Pony), associated-only (e.g., Bee-Honey), or semantic-and-associated (e.g., Doctor-Nurse). Controls showed greater priming of words related via two relationships (semantic-and-associated) than for words related only semantically.. However, patients showed greater priming for associated-only words than for words related only semantically. Schizophrenic patients may show an associational bias, restricting semantic integration and contributing to their disturbed thinking.
\end{abstract}

\section{Keywords}

Schizophrenia; Priming; Associational bias; Thought disorder

\section{Introduction}

Disturbed word associations in schizophrenia are often investigated by priming tasks that require speeded lexical decisions (word/non-word) to target letter strings that are preceded by word primes. Priming reflects faster lexical decisions for word targets preceded by related words than for unrelated words. Schizophrenic patients have shown reduced priming for related word pairs separated by relatively long intervals (see Minzenberg et al., 2002). Unclear, however, is the influence of different kinds of word-pair relationships on schizophrenic priming. For controls, priming is additive, greatest for word pairs related both semantically and associatively (e.g., Doctor-Nurse) than for words related only semantically (e.g., DeerPony) or associatively (e.g., Bee-Honey) (Chiarello et al., 1992). We now examine priming in schizophrenia in relation to these 3 kinds of prime-word relationships.

\footnotetext{
(C) 2005 Elsevier B.V. All rights reserved.

*Corresponding author. Psychiatry 116A, Brockton VAMC, 940 Belmont Street, Brockton, MA 02301, United States. Tel.: +1 508583 4500x1506; fax: +1 508580 0059. paul.nestor@umb.edu (P.G. Nestor).
} 


\section{Methods}

\subsection{Subjects}

All subjects were males between the ages of 17 and 55 years, right-handed, native speakers of English, without histories of ECT, neurological illness, and without alcohol or drug abuse in the past 5 years, as assessed by the Addiction Severity Index (McClellan et al., 1992). All subjects provided written informed consent. The Structured Clinical Interview for DSM-IV Axis I Disorders-Clinician Version (SCIDI: CV) (First et al., 1997a,b), along with chart review, ascertained the diagnosis of schizophrenia. Fourteen patients, all part of an ongoing comprehensive study of schizophrenia, participated. All patients were diagnosed with chronic schizophrenia, with a mean duration of illness of 18.6 years $(\mathrm{SD}=10.58)$, and were medicated, with a mean chlorpromazine (CPZ) daily dose of $613.70 \mathrm{mg}(\mathrm{SD}=370.62)$. Fourteen control subjects, recruited from newspaper advertisement, underwent the SCID-I: CV (First et al., 1997a,b) and the Structured Clinical Interview for DSM-IV Axis II Personality Disorders (SCIDII) (First et al., 1997a,b), and were matched to the patients on the basis of age, sex, handedness, and parental SES. Mean age did not differ significantly $(t=0.777, d f=81, p=$ 0.439 ) between patient ( 42.8 years, $\mathrm{SD}=10.96)$ and control (46.6 years, $\mathrm{SD}=6.54$ ) groups.

\subsection{Stimuli and task}

Following Chiarello et al. (1990), stimuli consisted of three sets of 48 related prime-target noun pairs, corresponded to three types of relationships: semantic-only (e.g., Deer-Pony), associated-only (e.g., Bee-Honey) and semantic-and-associated (e.g., Doctor-Nurse). Each of the three conditions (semantic-only, associated only, semantic-and-associated) included equal percentage of three types of trials: related, unrelated, and neutral. Unrelated fillers were included to maintain a low probability of prime-target relatedness (approximately $11 \%$ related trials). Orthographically legal non-word targets (four or five letters) were created by substituting one letter of a real word. Fifty percent of all trials had a non-word target. All stimuli were horizontally presented in uppercase using Times New Roman font, size 80. Stimuli appeared in black against white background.

\subsection{Apparatus and procedure}

The SuperLab Pro software package (2001) controlled stimulus presentation, timing of events, and recorded subjects' responses. Subjects sat $100 \mathrm{~cm}$ in front of a View Sonic Monitor. A

Gateway Computer, GP6-400 (Gateway Computer, Inc., Cupertino, CA), and registered their lexical decisions by pressing one of two buttons of a response pad (mouse). Half the subjects pressed their left thumbs for a word and their right thumbs for a non-word. For the other half of the subjects this response mapping was reversed. Subjects participated in three sessions, separated by a week, and each corresponded to one of the three conditions (semantic, associated, and semantic-and-associated), counterbalanced across all participants. Each session consisted of approximately 450 trials broken into 6 blocks of approximately 5-7 min long. Each block had 8 related, 8 unrelated, 8 neutral, and 16 filler trials, along with 40 nonword targets. Each of these trials began with a fixation marker (+) in the middle of the screen for duration of $1000 \mathrm{~ms}$, followed by a prime word for $75 \mathrm{~ms}$ duration. After a fixed $500 \mathrm{~ms}$ interval, a target (word or non-word) was displayed for $100 \mathrm{~ms}$. The next trial was initiated $1200 \mathrm{~ms}$ after the subject's response, or after $3000 \mathrm{~ms}$, if no response had occurred. Stimuli order was randomized. The subjects were told to focus on the fixation marker and to register their word/non-word decisions as accurately and quickly as possible. They were told that the first (prime) stimulus was a warning signal that the target item was about to appear. For each session, subjects completed block of 30 practice trials prior to the experiment. 


\section{Results}

For RT data comparing related and unrelated trials, a mixed-model analysis of variance (ANOVA) revealed significant effects for group, $F(1,26)=8.060, p=0.009$, trial type, $F(1,26)$ $=50.257, p<0.001$ and the interaction of trial type by condition, $F(2,52)=9.489, p<0.001$. Patients had slower overall slow RT, yet both groups had fastest RT for related trials in the associated-only condition. Analyses of accuracy data revealed no significant group difference (see Table 1).

Fig. 1 presents priming rates, calculated by subtracting RT of related from unrelated trials. Schizophrenic subjects had mean priming of $98 \mathrm{~ms}$ ( $\mathrm{SD}=85.067), 49.54 \mathrm{~ms}$ ( $\mathrm{SD}=51.06)$, and $71.50 \mathrm{~ms}$ ( $\mathrm{SD}=74.36)$ for association-only, semantic-only, and semantic-and-association conditions, respectively. Corresponding values for control subjects were $59.43 \mathrm{~ms}(\mathrm{SD}=24.01)$, $22.29 \mathrm{~ms}(\mathrm{SD}=26.86)$, and $70.18 \mathrm{~ms}(\mathrm{SD}=47.45)$ for association-only, semantic-only, and semantic-and-association conditions, respectively.

Fig. 2 presents mean percentage priming rates, calculated to control for overall slowness [UNRELATED-RE-RELATED/UNRELATED*100]: patients showed mean percentage priming rates of $10.84 \%, 5.51 \%$ and $8.7 \%$ compared to control values of $9.95 \%, 3.38 \%$, and $11.75 \%$ for association-only, semantic-only, and semantic-and-association conditions, respectively. Paired $t$-tests revealed that the patient group showed greatest priming for associated-only related word pairs, which differed significantly from priming of word pairs related only by semantic category, $t(13)=2.801, p=0.015$. By contrast, controls showed greatest priming for word pairs related via both semantic category and association, which differed significantly from priming of word pairs related only by semantic category, $t(13)=3.279, p$ $=0.006$. Controls also showed greater priming for associated-only word pairs in comparison to semantic-only word pairs, $t(13)=4.638, p<0.001$.

\section{Discussion}

Patients and controls showed evidence of different within-group patterns of priming for words pairs related associatively, semantically, or by both these dimensions. Consistent with previous studies (see Lucas, 2000), both groups showed their lowest levels of priming for semantic-only word pairs. Likewise, for both groups, priming did not differ significantly for associated-only versus semantic-and-associated words. However, the controls showed significantly greater priming for semantic-and-associated word-pair relationships in comparison to words related only semantically. By contrast, the patients showed greater priming for associated-only word pairs in comparison to semantic-only word pairs. That the controls showed greater priming for semantic-and-associated words than for words related only semantically may reflect an additive priming effect. This effect in patients may be weakened, perhaps due to an associational bias that leads to restricted semantic integration and contributes to disturbed thinking. (e.g., Chapman and Chapman, 1973; Nestor et al., 1998; Han et al., 2003). However, the current findings are limited, demonstrated as statistically significant on the basis of within- but not between-group analyses. Future studies will require greater statistical power to establish the hypothesized reduced semantic additivity by between-group analyses, specifically the interaction of group by word-pair relationship.

\section{References}

Chapman, LJ.; Chapman, JP. Disordered Thought in Schizophrenia. Prentice Hall; Englewood Cliffs, NJ: 1973.

Chiarello C, Burgess C, Richards L, Pollock A. Semantic and associative priming in the cerebral hemispheres: some words do, some words don't. . Sometimes, some places. Brain and Language 1990;38:75-104. [PubMed: 2302547] 
Chiarello C, Richards L, Pollock A. Semantic additivity and semantic inhibition: dissociable processes in the cerebral hemispheres? Brain and Language 1992;42:52-76. [PubMed: 1547469]

First, MB.; Spitzer, RL.; Gibbon, M.; Williams, JBW. Structured Clinical Interview for DSM-IV Axis I Disorders-Clinician Version (SCID-I: CV). American Psychiatric Press; Washington, DC: 1997a.

First, MB.; Gibbon, M.; Spitzer, RL.; Williams, JBW.; Benjamin, LS. Structured Clinical Interview for DSM-IV Axis II Personality Disorders (SCID-II). American Psychiatric Press; Washington, DC: 1997b.

Han SD, Nestor PG, Shenton ME, Niznikiewicz M, Hannah G, McCarley RW. Associative memory in chronic schizophrenia: a computational model. Schizophrenia Research 2003;61:255-263. [PubMed: 12729877]

Lucas M. Semantic priming without association: a meta-analytic review. Psychonomic Bulletin and Review 2000;1:618-630. [PubMed: 11206202]

McClellan AT, Kushner H, Metzger D, Peters R, Smith L, Grissom G, et al. The fifth edition of the Addiction Severity Index. Journal of Substance Abuse Treatment 1992;9:199-213. [PubMed: 1334156]

Minzenberg MJ, Ober BA, Vinogradov S. Semantic priming in schizophrenia: a review and synthesis. Journal of International Neuropsychology 2002;8:699-720.

Nestor PG, Akdag SJ, O’Donnell BF, Niznikiewicz MA, Law S, Shenton ME, McCarley RW. Word recall in schizophrenia: a connectionist model. American Journal of Psychiatry 1998;155:1685-1690. [PubMed: 9842776]

SuperLab Pro [Computer Software]. Cedrus Corporation; San Pedro, CA: 2001. 


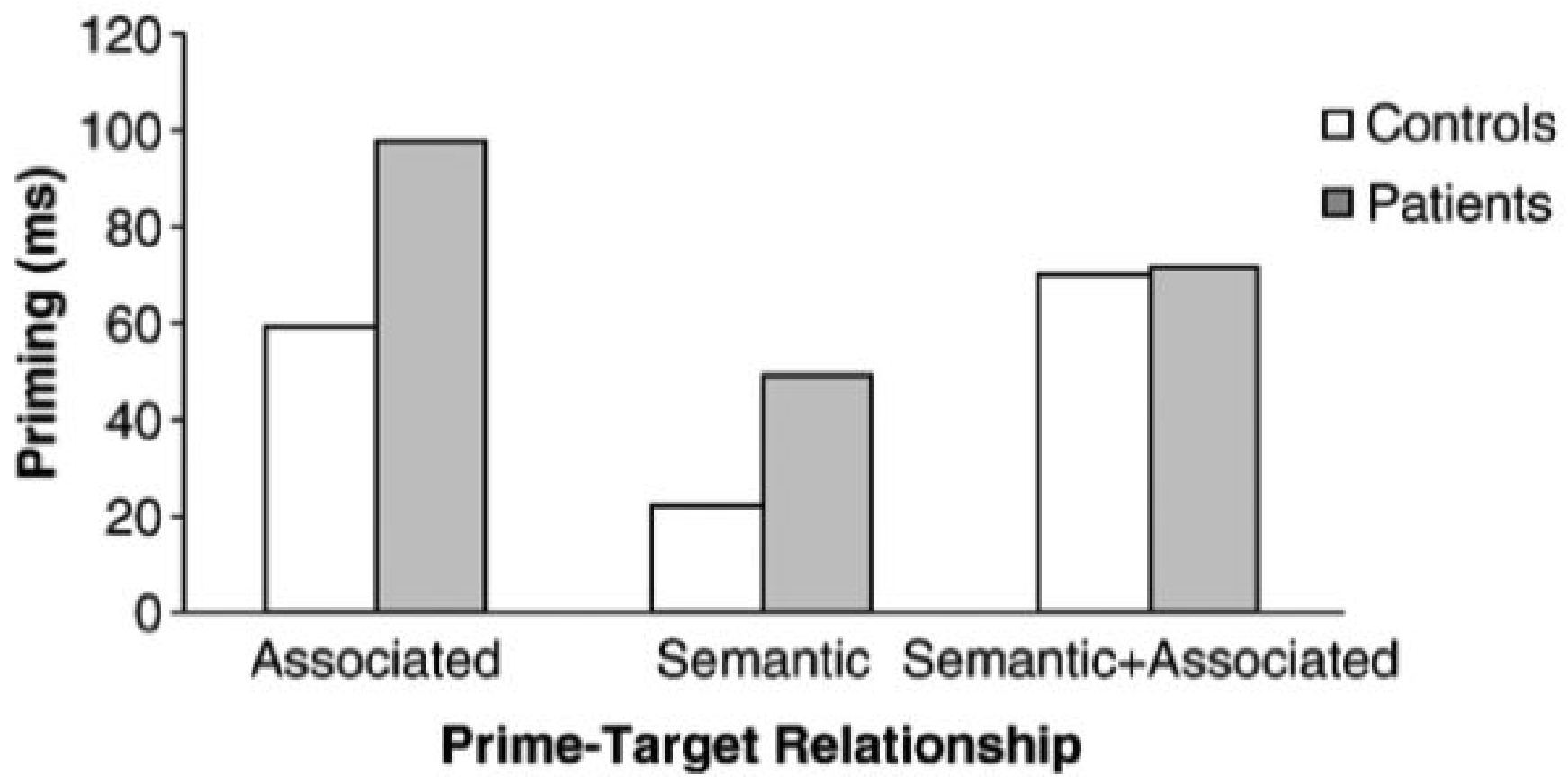

Fig. 1.

Priming effect (RT unrelated RT - related) for patient and control groups. 


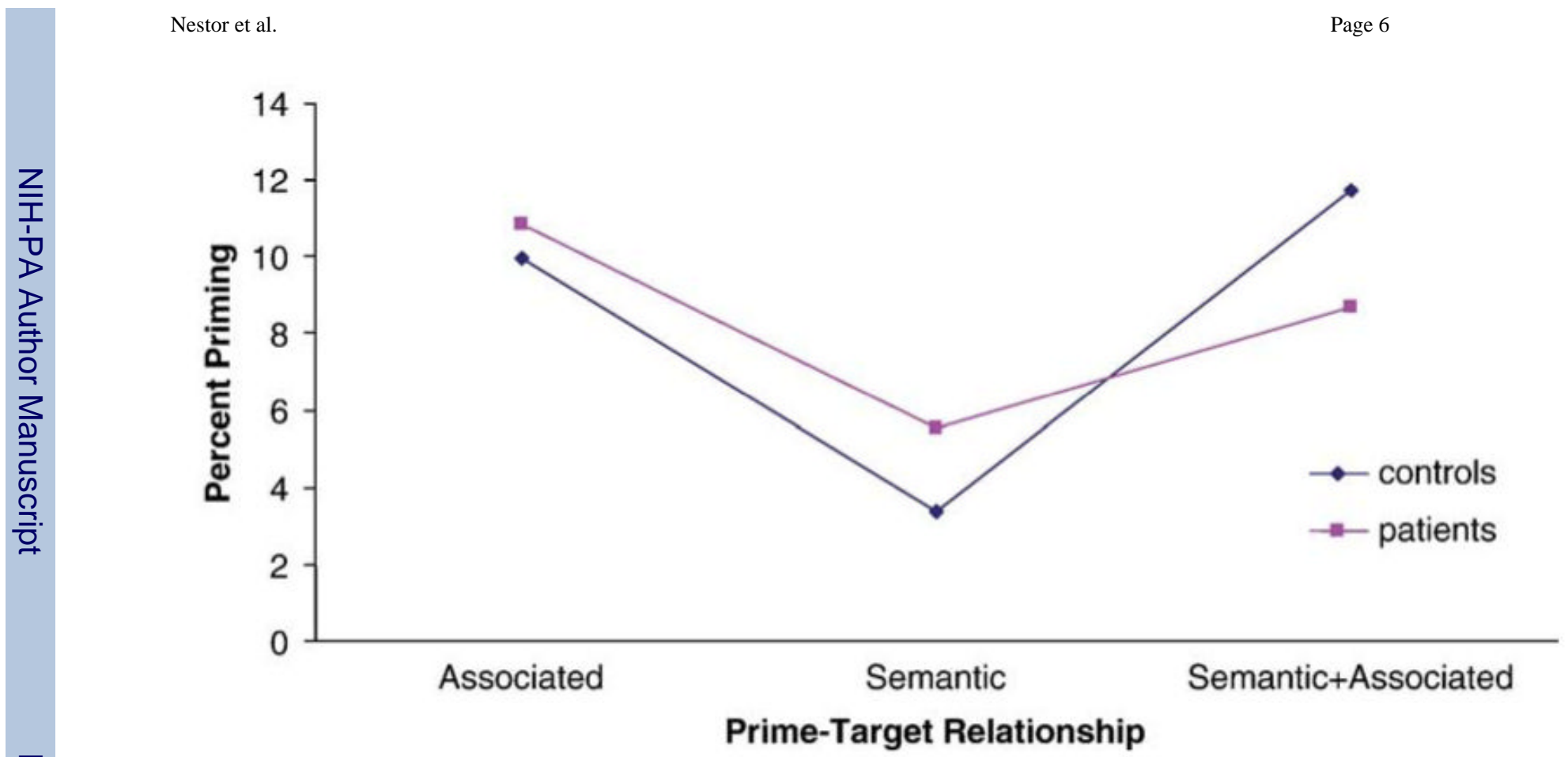

Fig. 2.

Mean percent priming for patient and control groups. 


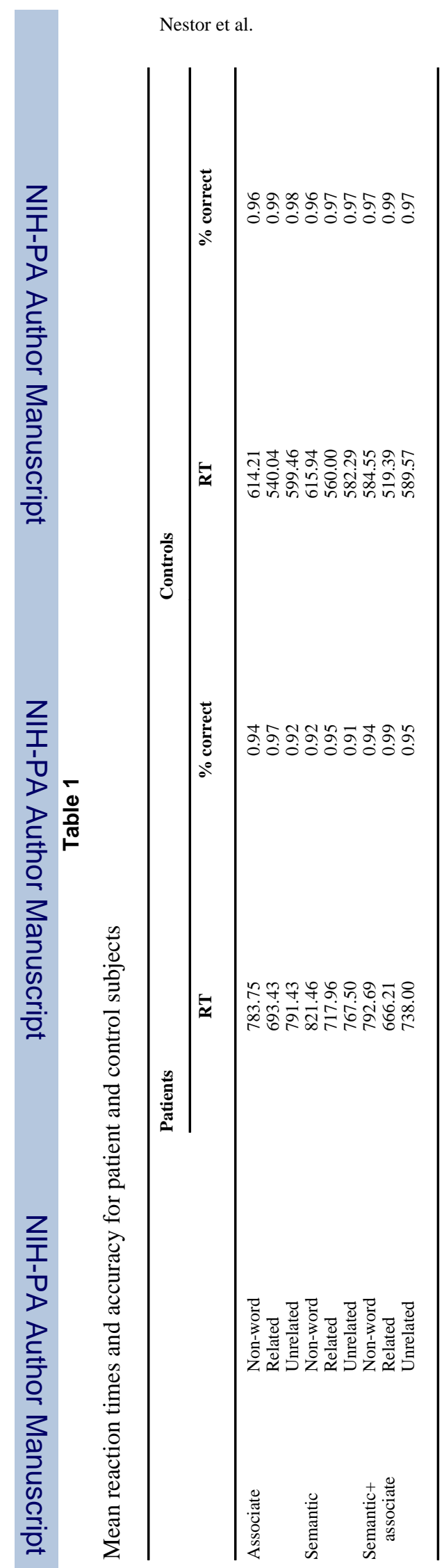

Page 7 